\title{
CLASSIFICAÇÃo DE LÂMINAS DE MADEIRA DE Pinus spp. CONTAMINADAS POR FUNGOS MANCHADORES ${ }^{1}$
}

\author{
Mayara Elita Carneiro², Washington Luiz Esteves Magalhães ${ }^{3}$, Nisgoski Silvana² e Graciela Inês Bolzon \\ Muñiz ${ }^{2}$
}

\begin{abstract}
RESUMO - A busca por novas tecnologias que garantam a uniformidade da qualidade dos produtos tem se tornado constante, assim este trabalho teve como objetivo estudar a potencialidade de medidas espectroscópicas combinadas a ferramentas estatísticas para classificação de lâminas de madeiras de Pinus spp. contaminadas por fungos manchadores. As amostras foram coletadas em processo industrial, e observou-se que algumas lâminas estavam contaminadas por fungos manchadores. Assim, utilizou-se este material para investigar a influência dessa mancha azul em metodologias espectroscópicas e a possibilidade de discriminação dessa contaminação. Desse material contaminado foram capturados os espectros, na faixa de 400 a $1000 \mathrm{~nm}$. Com esses dados, realizou-se uma análise exploratória por Componentes Principais (PCA) e classificação via SIMCA, em que se verificou a discriminação eficiente em dois grupos, madeiras sadias e contaminadas. Observou-se que a técnica de espectroscopia óptica preenche os requisitos necessários para uma possível aplicação na classificação de lâminas no processo produtivo.
\end{abstract}

Palavras-chave: Espectroscopia óptica, Análise por Componentes Principais, SIMCA.

\section{CLASSIFICATION OF Pinus spp. VENEERS WOOD CONTAMINATED BY BLUE STAIN FUNGI}

\begin{abstract}
The search for new technologies that ensure uniformity of product quality has become constant. The objective of this work was to study the potential of spectroscopic measurements combined with statistical tools for sorting sheets of wood of Pinus spp. contaminated by staining fungi. Samples were collected in the industrial process and it was found that some blades were contaminated by fungus staining. Thus, this material was used to investigate its influence on blue stain and spectroscopic methods and the possibility of discrimination by such contamination. Spectra at 400-1000 m range were captured from this contaminated material. By using these data, it was performed an exploratory analysis by Principal Components (PCA) and classification via SIMCA, where discrimination was found effective in healthy and diseased wood. It is observed that the use of optical spectroscopy fulfills the requirements for possible use in classifying blades in the production process.
\end{abstract}

Keywords: Optical spectroscopy, Principal Component Analysis, SIMCA.

\section{INTRODUÇÃO}

A descoloração por fungos manchadores na madeira do gênero Pinus tornou-se um grande problema para a indústria de base florestal, sendo a mancha azul a mais comum (NICHOLAS, 1973). Vários trabalhos destacam esses fungos como os principais responsáveis pelas grandes perdas de material, especialmente durante as fases de abate e desdobro das toras (CROAN; HIGHLEY, 1991; HANSEN; MORRELL, 1997; KREBER et al., 2001).

Entre os fungos manchadores existe um grupo denominado "azuladores" ou "blue stain fungi", devido à pigmentação que acarretam na madeira. A colonização por esses agentes resulta no manchamento da madeira,

\footnotetext{
${ }^{1}$ Recebido em 29.03.2012 aceito para publicação em 09.04.2013.

2. Departamento de Engenharia e Tecnologia Florestal da Universidade Federal do Paraná, UFPR, Brasil. E-mail:<mayaraelita@ufpr.br>, <graciela.ufpr@gmail.com> e < silvana.ufpr@gmail.com>.

${ }^{3}$ Embrapa Florestas, Brasil. E-mail:<washington.magalhaes@embrapa.br>.
} 
devido à produção e deposição de metabólitos secundários, como grânulos de melanina (BRUCE et al., 2003; DOGRA; BREUIL, 2004). Esses fungos são demáceos e filamentosos e possuem melanina na parede celular de suas estruturas. A melanina apresenta em sua composição química altos teores de concentração de nitrogênio (ZINK; FENGEL, 1990).

Historicamente, a única maneira de medir esse manchamento, principalmente no campo, é pela inspeção visual (GOODISON; HSIELH, 2007). O desenvolvimento de uma técnica instrumental para discriminar esse manchamento é de grande utilidade prática, visando à melhoria no controle de qualidade dos produtos madeireiros a baixo custo.

Vários autores vêm pesquisando onde e como ocorre à interferência da mancha azul em medidas espectroscópicas e a influência delas em modelos de calibração multivariada (ZULPA et al., 2003; ZHOU; WANG, 2003; VIA, 2004; VIA et al., 2006).

O uso da espectroscopia no visível (Vis) e no infravermelho próximo (NIR) combinado a ferramentas estatísticas multivariadas vem se tornando um método rápido para previsão das propriedades da madeira (SCHIMLECK et al., 2007).

Existem diversas técnicas de estatística multivariada, com as mais variadas aplicações, destacando-se a análise de componentes principais (PCA), método que se baseia na análise de dados visando à sua redução, por meio de escolhas mais representativas a partir de combinações lineares das variáveis originais. Outra técnica utilizada para caracterização de grupos de amostras é o SIMCA (do inglês "Soft Independent Modeling of Class Analogy"). O SIMCA é um método de reconhecimento de padrões baseados na similaridade. Considera para a classificação informações da distribuição da população, estima um grau de confiança da classificação e pode prever novas amostras como pertencentes a uma ou mais classes ou nenhuma classe.

Na literatura há diversas aplicações dessa técnica bem-sucedidas. Parizzi et al. (2004) utilizaram a classificação SIMCA para detecção de defeitos e fungos em grãos de café, em substituição à técnica visual. Schimleck et al. (2000) usaram SIMCA para classificação de madeiras de lenho juvenil e adulto. Lebow et al. (1996), através da espectroscopia Vis, relataram ser possível a identificação de características macroscópicas como nós, esmoados, manchas de fungo, apodrecimento, madeira de compressão, anéis de crescimento e outros em laminados de Pseudotsuga menzeisii.

Este trabalho teve como objetivo a classificação de lâminas de madeira de Pinus spp. pela contaminação por fungos manchadores, utilizando-se medidas espectroscópicas.

\section{MATERIAL E MÉTODOS}

A obtenção das amostras foi realizada na Indústria de Compensados e Laminados Lavrasul, localizada na cidade de Canoinhas, no Estado de Santa Catarina. No processo industrial dessa empresa, no setor de classificação foram coletadas lâminas torneadas de madeira de Pinus spp. com idade aproximada de 30 anos. Com as lâminas industriais foram confeccionados corpos de prova com dimensões de 185 × 24 × $2 \mathrm{~mm}$, e um total de 100 amostras foram selecionadas, sendo 50 isentas de qualquer defeito e, as outras 50, apresentando "azulamento". Na tentativa de discriminar esses grupos de amostras foram coletados espectros, em espectrofotômetro NIRS USB2000 Miniature Fiber Optic Spectrometer, instrumento que opera no modo de refletância difusa $(\log 1 / \mathrm{R})$ na faixa de $400-1.000$ nm com varreduras em 0,37 em 0,37 nm, através do software Ocean Optics.

Para o processamento dos espectros foi utilizado o programa The Unscrambler (versão 9.2; CAMO A/ S, USA). Para uma análise exploratória, foi realizada uma análise dos dados espectrais, empregando-se a Análise por Componentes Principais (PCA) para 72 amostras no total de 36 amostras livres de defeitos (1 a 36) e 36 amostras infectadas pela mancha azul (37 a 72). Em uma análise de componentes principais, a dimensão dos dados originais é diminuída para um menor conjunto de dimensões chamadas de Componentes Principais (PCs). A partir dos PCs são gerados dois novos conjuntos de dados chamados de scores e loadings. Graficamente, esses dois conjuntos trazem, respectivamente, informações sobre as amostras e as variáveis espectrais. Assim, podem-se identificar possíveis interferências, ocasionadas nas lâminas decorrentes da mancha azul.

A partir dessa análise por PCA, em que se verificou a distinção de classes, foram construídos modelos PCA para os conjuntos de amostras contaminadas e isentas que serviram como padrão para uma classificação SIMCA. 
Para avaliar a capacidade preditiva desses modelos foram empregadas 28 amostras, sendo 14 amostras para cada tipo de amostragem (que não fizeram parte do procedimento de calibração). O SIMCA fornece como resultado uma tabela, onde as amostras são classificadas e a que classes essas amostras pertencem.

Para analisar o grau de contaminação, a anatomia do ataque e a interação desses fungos manchadores nas lâminas de madeira foram obtidas imagens em Microscópio Eletrônico de Varredura da Marca HITACHI, modelo TM-1000.

\section{RESULTADOS}

A Figura 1 ilustra os espectros normalizados e centrados na média, na região do espectro visível e short NIR, das lâminas de madeira para as amostras isentas de qualquer defeito e daquelas contaminadas por fungos manchadores.

O método PCA foi aplicado inicialmente para observar se há distinção (separação em classes) entre a amostragem estudada amostras atacadas por fungos manchadores e amostras livres de defeitos. Essa análise PCA contendo 72 espectros das lâminas de madeira foi construída, sendo as amostras 1 ao 36 isentas de qualquer defeito as 37 ao 72, atacadas por fungos manchadores.

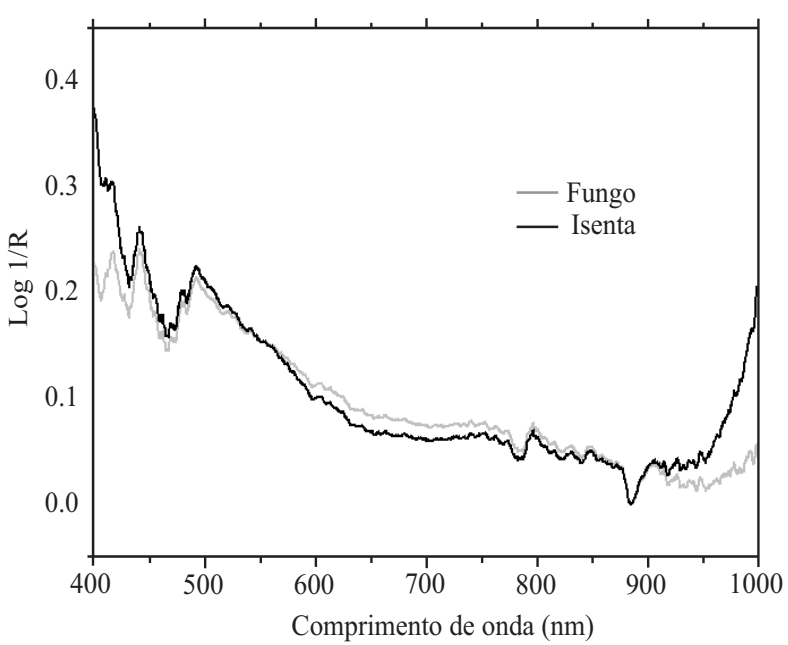

Figura 1 - Espectros das amostras de lâminas de madeira contaminadas por fungos manchadores (cinza) e isentas da contaminação (preto).

Figure 1 - Spectra of samples of veneers infected by fungi staining (gray) and free of contamination (black).
Na Figura 2A é mostrado o gráfico de escores da primeira, segunda e terceira componentes principais, obtido para as lâminas de madeira, enquanto a Figura 2B contém o gráfico de loadings.

A Tabela 1 ilustra a classificação que cada espectro recebeu $(*)$, em que as amostras numeradas de 1 a 14 são espectros isentos, e F1 a F14 são espectros de fungos manchadores. Essa tabela de resultados das classificações SIMCA mostra que todas as amostras do conjunto de predição foram classificadas corretamente ( $100 \%$ de acerto em nível de confiança de $95 \%$ ) para os dois modelos SIMCA, o que demonstra a boa capacidade preditiva desses modelos. Na validação, observou-se que todas as amostras do conjunto de validação foram classificadas corretamente em seu próprio modelo SIMCA.

Essa classificação também é representada no gráfico $\mathrm{Si} / \mathrm{SO}$ x Leverage (Figura 3). No gráfico de $\mathrm{Si} / \mathrm{So}$ x Leverage (Hi), $\mathrm{Si} / \mathrm{So}$ é a distância relativa da nova amostra ao modelo (desvio-padrão residual), e Hi é a projeção da distância da amostra ao centro do modelo. A amostra é considerada como pertencendo à classe modelada se ambas as distâncias medidas $\mathrm{Si} / \mathrm{So}$ e Hi forem menores que um valor crítico de distância da classe modelada. O resultado é fornecido para cada classe separadamente. Quando uma nova amostra obtém valores de distâncias superiores aos valores estipulados para cada classe, a amostra é classificada como não pertencendo a nenhuma classe. Esse tipo de classificação é normalmente realizado com uma confiabilidade de $95 \%$ de um resultado correto (significância de 5\%). Para o caso estudado, apresenta uma classificação sem erros das amostras em suas classes, evidenciando, assim, o potencial de identificação e discriminação dessa técnica.

Nas amostras contaminadas (indicadas na Figura 3), observa-se discriminação pelo grau de contaminação. As amostras F10 e F11 apresentaram o manchamento em estágio inicial. Já as amostras F8, F6 e F1 exibiram estágio intermediário de contaminação, e as demais amostras apresentaram alto grau de contaminação, segundo a classificação visual prévia. Dessa maneira, é possível a discriminação pelo grau de contaminação desses fungos manchadores.

Para confirmar o grau de ataque, as amostras F10, F2 e 11 foram submetidas à análise por microscopia eletrônica. A Figura 4 mostra as fotomicrografias MEV;

Revista Árvore, Viçosa-MG, v.37, n.2, p.369-375, 2013 

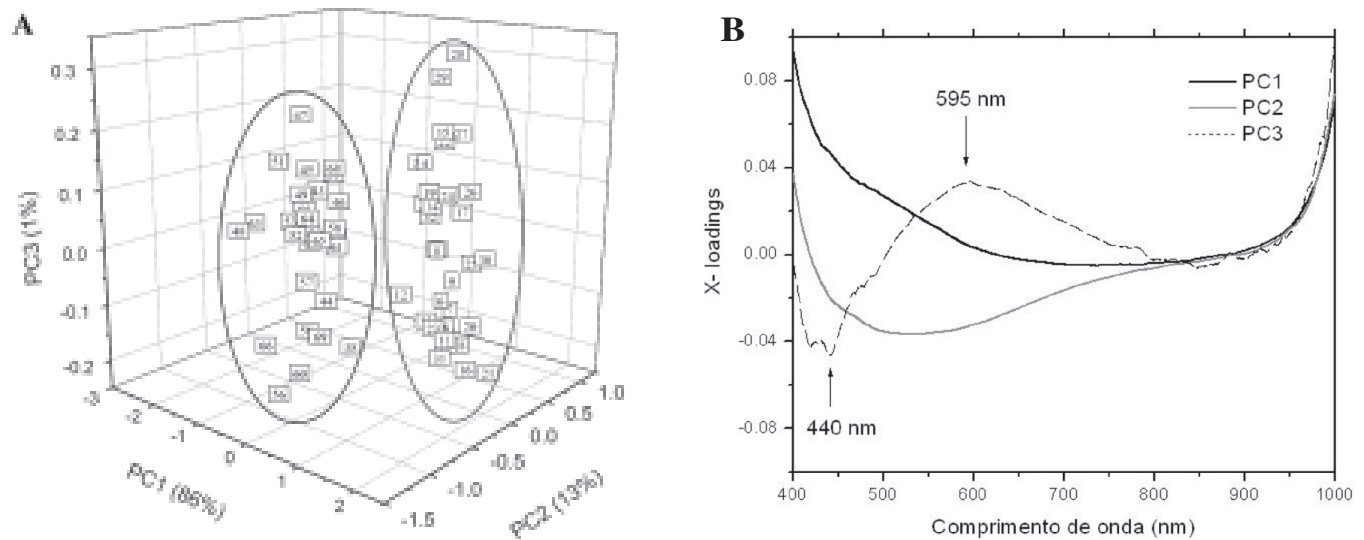

Figura 2 - Análise por componentes principais para as lâminas de madeira isenta e contaminadas por fungos manchadores A. Gráfico de scores. B. Gráfico de loadings.

Figure 2 - Principal component analysis for free and wood staining fungi contaminated blades $\boldsymbol{A}$. Graphic scores. $\boldsymbol{B}$. Graphic loadings.

Tabela 1 - Classificação de amostras externas (não utilizadas nos modelos de calibração) de contaminadas e isentas dos fungos manchadores. $\mathrm{O}$ asterisco $(*)$ significa que o espectro foi classificado como pertencendo ao modelo.

Table 1 - Classification of outer samples (not used in the calibration model) of infected and staining fungi free wood. The asterisk (*) means that the spectrum has been classified belonging to the model.

\begin{tabular}{ccc}
\hline Amoatra & PCA Fungo & PCA Isenta \\
\hline 1 & & $*$ \\
2 & & $*$ \\
3 & & $*$ \\
4 & & $*$ \\
5 & & $*$ \\
6 & & $*$ \\
7 & & $*$ \\
8 & & $*$ \\
9 & & $*$ \\
10 & & $*$ \\
11 & & \\
12 & & \\
13 & \\
14 & $*$ & \\
F1 & $*$ & \\
F2 & & \\
F3 & $*$ & \\
F4 & $*$ & \\
F5 & $*$ & \\
F6 & $*$ & \\
F7 & $*$ & \\
F8 & $*$ & \\
F9 & $*$ & \\
F10 & $*$ & \\
F11 & $*$ & \\
F12 & $*$ & \\
F13 & $*$ & \\
F14 & $*$ & \\
\hline
\end{tabular}

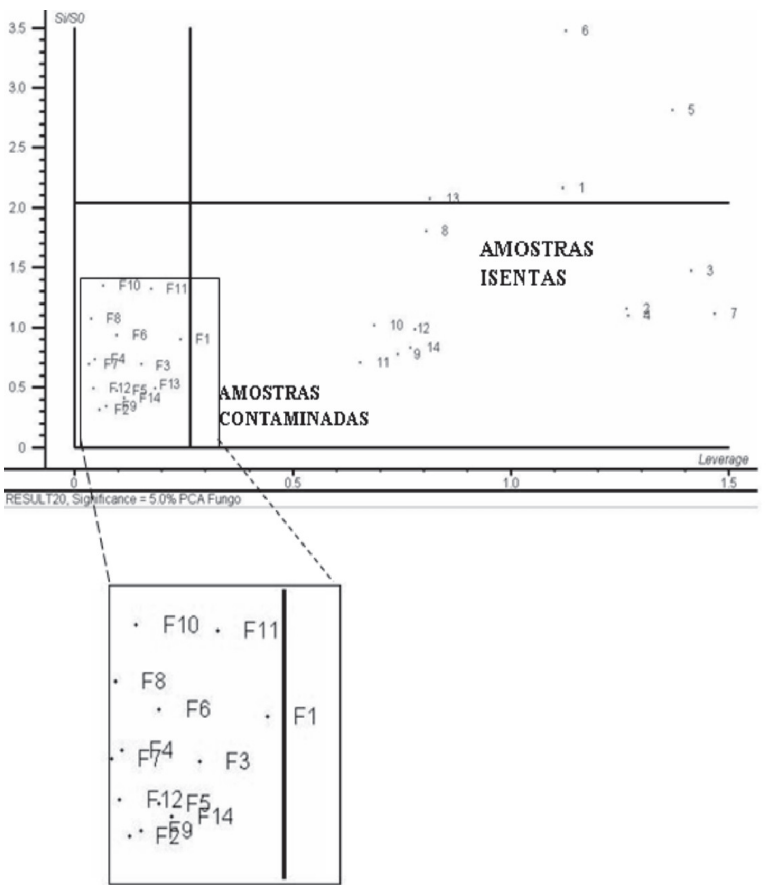

Figura 3 - Gráfico de SI/SO x Leverage da classificação dos espectros de lâminas de madeiras isentas e contaminadas pela mancha azul. No detalhe, a classificação das amostras contaminadas e indicação do grau de contaminação.

Figure 3 -SI/SO x Leverage graphic for classification of the spectra of layers of free and blue stain contaminated wood. Classification of contaminated samples and indication of the contamination degree are detailed.

Revista Árvore, Viçosa-MG, v.37, n.2, p.369-375, 2013 

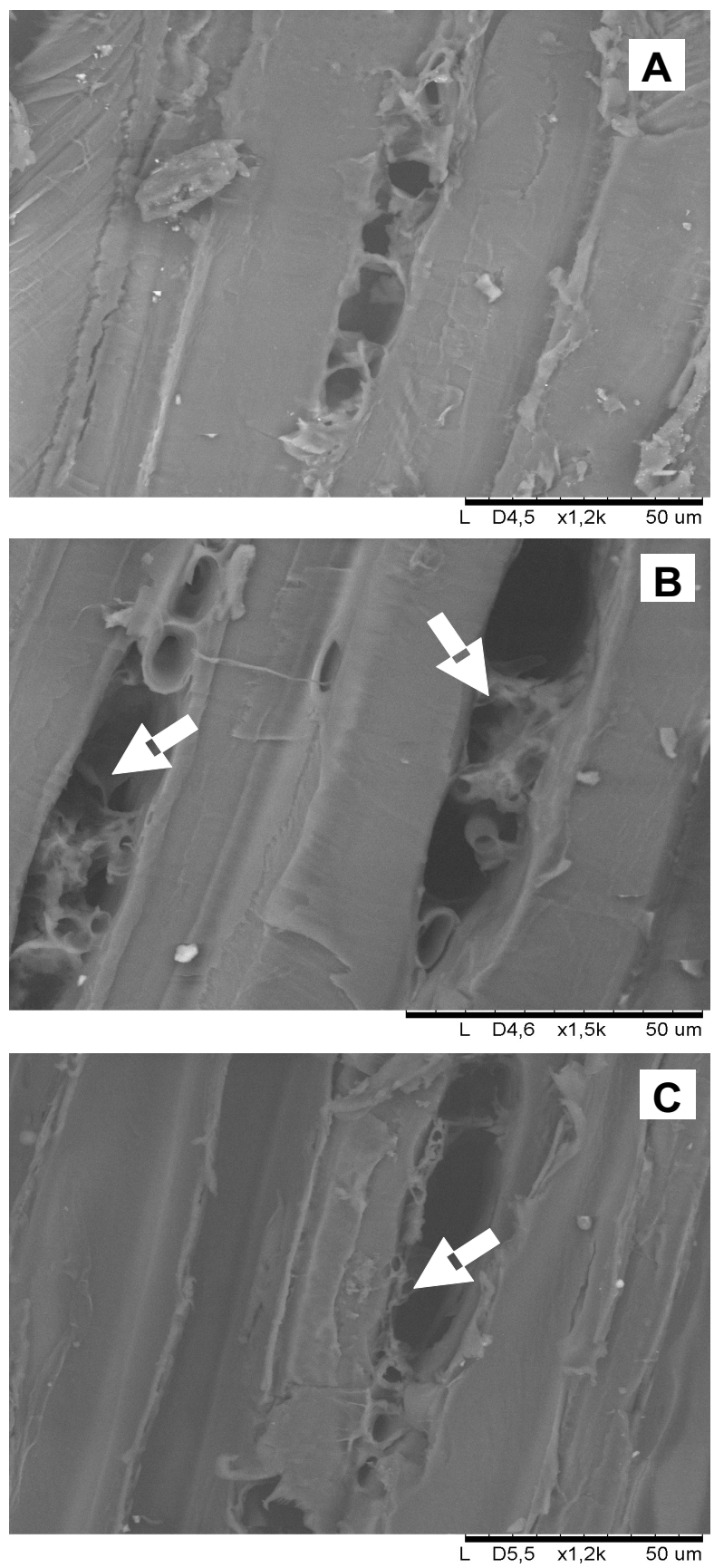

Figura 4 - Fotomicrografias em microscópio eletrônico de varredura (MEV) das lâminas de madeira. A. Amostra Sadia (11) B. Amostra muito contaminada (F2)C. Amostra pouco contaminada (F10).

Figure 4-Photomicrographs of scanning electron microscope (SEM) of the wood blades. A. Sample free of defects (11). B. Strongly contaminated sample (F2).C. Slightly contaminated sample (F10). com isso, é possível visualizar a interação anatômica dos fungos manchadores com as lâminas de madeira.

Na Figura 4A, observa-se a amostra sadia (11), com a visualização das células do parênquima radial. A Figura 4B (amostras F2) evidencia o rompimento das células do parênquima radial, a presença de um conjunto de hifas e o micélio, em maior grau. Na Figura 4C (amostra F10), observam-se também o rompimento das células do parênquima radial e a formação de pequenas hifas. As fotomicrografias das amostras contaminadas confirmam como ocorre o ataque desses fungos manchadores. As hifas penetraram na madeira, colonizando quase que exclusivamente as células do parênquima radial, sendo raramente observadas nos traqueoides. Segundo Hunt e Garrat (1962) e Eaton e Hale (1993), a passagem dessas hifas de uma célula para outra ocorre através das pontoações.

\section{DISCUSSÃO}

Neste modelo PCA desenvolvido, observa-se a discriminação das amostras em duas classes, separação entre as lâminas isentas de defeitos e as lâminas contaminadas por fungos.

Na Figura 2B, a PC1 (preto) explica $86 \%$ da variância total dos dados e mostra o mesmo aspecto dos espectros das amostras isentas dos fungos. A PC2 (cinza) que explica

$13 \%$ da variância total dos dados em $X$, por sua vez, mostra aspectos dos espectros das amostras contaminadas por fungos. A PC3 (hachurada), Figura $2 \mathrm{~B}$, explica $1 \%$ da variância total e apresenta as bandas com maior intensidade nos comprimentos de onda indicados, 440 e $595 \mathrm{~nm}$. Regiões do espectro visível característicos pela absorção dos grupos cromóforos (azul e ciano), sendo responsáveis pela coloração desses manchamentos azulados.

Com informações espectroscópicas na faixa que compreende de 400 a 1.100nm, há a possibilidade de identificação de fungos manchadores em diferentes graus de ataque. A espectroscopia, aliada a técnicas de análise multivariada, possivelmente poderá ser utilizada como sensores em processos de industrialização da madeira, controlando e monitorando em tempo real a qualidade do produto.

Revista Árvore, Viçosa-MG, v.37, n.2, p.369-375, 2013 


\section{CONCLUSÕES}

Com base nos resultados deste trabalho, pode-se concluir que:

- A faixa espectral de maior interferência corresponde às absorções dos grupos cromóforos responsáveis pelas cores azul e ciano, cores bem características desses fungos manchadores.

- As medidas espectroscópicas podem ser empregadas para separar as madeiras contaminadas por fungos manchadores e as isentas.

\section{REFERÊNCIAS}

BRUCE, A. et al. Effect of volatiles from bacteria and yeast on the growth and pigmentation of sapstain fungi. International Biodeterioration and Biodegradation, v.51, p.101-108, 2003

\section{CROAN, S. E.; HIGHLEY, T. L. Antifungal} activity in metabolites from Streptomyces rimosus. Stockholm: International Research Group on Wood Preservation, IRG/WP/ 1440, 1991.

DOGRA, N.; BREUIL, C. Suppressive substractive hybridization and differential screening identified genes differentially expressed in yeast and mycelial forms of Ophiostoma piceae. Federation of European Microbiological Societies (FEMS) - Microbiology Letters, v.238, n.1, p.175-181, 2004.

GOODISON, A.; HSIELH, E. Quantifying blue stain usinig vis- nir spectroscopy.

PAPRICAN. Disponível em: (http:// wcm.paprican.ca/wcmpaprican/publishing.nsf/ AttachmentsByTitle/

EV_EvaluTree_Blue_Stain_Eng/\$FILE/

E_EvaluTree_Blue_Stain.pdf). Acesso em: $12 \mathrm{de}$ abr. de 2007.

HANSEM, J.; MORRELL, J. J. Use of anti-stain chemical treatments by Western U.S. softwood lumber industry. Forest Products Journal, v.47, n.6, p.69-73, 1997.

HUNT, G. M.; GARRATt, G. A. Preservacion de la madera. Barcelona: Salbat Editores, 1962. p.41-51.

Revista Árvore, Viçosa-MG, v.37, n.2, p.369-375, 2013
EATON, R. A.; HALE, M. D. Wood decay, pest, and protection. London: Chapman \& Hall, 1993. p.546.

KREBER, B. et al. Arrest of fungal pré-infections in raw logs and freshly sawn lumber of radiata pine using Sentry. Forestry Products Journal, v.51, n.10, p.66-72, 2001.

LEBOW, P. K. et al. Classifications of surface features y spectral relectance. Wood and Fiber Science, v.28, n.1, p.74-90, 1996.

NICHOLAS, D. D. Wood deterioration and its prevention by preservative treatments. Degradation and protection of wood. New York: Syracuse University Press, 1973. v.1.380p.

PARIZZI, F. C. et al. Espectroscopia de infravermelho próximo na detecção de defeitos e fungos em grãos de café. In: SEMINÁRIO NACIONAL DE ARMAZENAGEM, 4., 2005, Uberlândia, 2005. Anais... Uberlândia: 2005.

SCHIMLECK, L. R.; MICHELL, A. J.; RAYMOND, C. A. Effect of site on the withintree variation of wood properties of eucalypts as determined by NIR spectroscopy and multivariate analysis. Appita Journal, v.53, n.4, p.318-32, 2000.

SCHIMLECK, L. R. et al. Microfibril angle prediction of Pinus taeda wood samples based on tangencial face NIR spectra. IAWA Journal, v.28, n.1, p.1-12, 2007.

VIA, B. K. Modeling longleaf pine (Pinus palustris mill) wood properties using near infrared spectroscopy. 2004. 141f. Tese (Doctor of Philosophy) - Agriculture and Mechanical College, The School of Renewable Natural Resources, Louisiana State University, 2004.

VIA, B. K. et al. The response of visible/near infrared absorbance to wood-staining fungi. Wood and Fiber Science, v.38, n.4, p.717726, 2006.

ZHOU, Q.; WANG, J. Leaf and spike reflectance spectra of rice with contrasting nitrogen supplemental levels. International Journal Remote Sensing, v.24, n.7, p.1587-1593, 2003. 
ZINK, P.; FENGEL, D. Studies on the colouring matter of blue-stain fungi. Part 3. Spectroscopic studies on fungal and synthetic melanins.

Holzforschung, v.44, n.3, p.163-168, 1990.
ZULPA, G. et al. Bioactivity of intra and extracellular substances from cianobacteria and lactic acid bacteria on "Wood blue stain" fungi. Biological Control, v.27, n.3, p.345-348, 2003. 
